\title{
Adição de escória de alto forno em argamassas colantes tipo AC-I
}

\section{(High oven slag addition in tile adhesive type AC-I)}

\author{
J. Rossa Jr. ${ }^{1}$ K. F. Portella ${ }^{2}$ \\ ${ }^{1}$ Departamento de Engenharia, Universidade Federal do Paraná, CP 19011, Curitiba, PR 81531-990 \\ ${ }^{2}$ Departamento de Tecnologia em Materiais, Instituto de Tecnologia para o Desenvolvimento, CP 19067, \\ Curitiba, PR 81531-980
}

\begin{abstract}
Resumo
Neste estudo foi investigado o uso da adição da escória de forno em argamassa colante tipo ACI, em substituição ao cimento de Portland. Os aspectos físicos e químicos (difração de raios X, fluorescência de raios X, microscopia eletrônica de varredura e análise por dispersão de elétrons) de três composições de escória de diferentes partes do Brasil foram estudados, usando a escória de menor reatividade. Os resultados indicaram a potencialidade do seu uso, com resistência de aderência à tração similar às amostras de referência e mais altas do que as recomendações normativas.

Palavras-chave: argamassa colante, escória, cimento Portland.
\end{abstract}

\begin{abstract}
In this study the use of high oven slag addition in tile adhesives, type AC-I, in place of Portland's cement parts of mass was investigated. The physical and chemical aspects (XRD, XRF, SEM and EDS) of three compositions of different parts from Brazil slag were studied, using the less reactivity slag. The results indicated the potentiality of use, with similar adherence strain stress to reference samples and higher than the standard recommendation.
\end{abstract}

Keywords: tile adhesives, slag, Portland cement.

\section{INTRODUÇÃO}

A química do cimento Portland com adição da escória de alto forno: A escória de alto forno é um subproduto do processo metalúrgico (com geração estimada entre 70 a $170 \mathrm{~kg} / \mathrm{t}$ aço bruto) [1], obtido durante a fundição dos metais, quando as impurezas são separadas e removidas em diversas faixas granulométricas. A sua constituição química corresponde a uma mistura de óxidos, silicatos metálicos, metais nas suas formas elementares, tendo como componentes básicos os óxidos de $\mathrm{Ca}, \mathrm{Fe}, \mathrm{Mg}$ e Al, dentre outros [2]. Por conter sua composição química parecida com a do clínquer de cimento Portland, com quantidades consideráveis de silicato dicálcico, $\mathrm{Ca}_{2} \mathrm{SiO}_{4}$, ou na química do cimento, $\mathrm{C}_{2} \mathrm{~S}$ por vezes silicato tricálcico, $\mathrm{Ca}_{3} \mathrm{SiO}_{5}$ ou $\mathrm{C}_{3} \mathrm{~S}$, e, também, $\mathrm{CaO}$ livre (componente, prejudicial pela possibilidade de causar reações expansivas) ao ser prétratada e adicionada aos cimentos, promove mudanças nas suas propriedades, tais como a minimização da reação álcali agregado, da permeabilidade, do calor de hidratação, da retração por secagem e o aumento da resistência a sulfatos e da resistência à compressão para idades mais avançadas. A substituição parcial do calcário para a formação do clínquer pela escória tem trazido vantagens na economia de energia devido sua redução do calor e a diminuição da formação de gases, especialmente, o $\mathrm{CO}_{2}$, nocivo à atmosfera [3]. Reschke [4], estudando a utilização da escória granulada de fundição, nas proporções de $0 \%, 10 \%, 30 \%$ e $50 \%$, em substituição ao cimento Portland, em concretos na construção civil, concluiu que para a mesma relação água/aglomerante, a sua substituição aumentou a taxa de absorção de água, mas não influenciou no aumento da taxa de penetração de íons cloreto. Entretanto, para um mesmo valor de resistência à compressão, esta diminuiu também a taxa de absorção e a penetração de cloretos. Chamon [5] estudou a influência de adições de sílica ativa gel, escória de alto forno granulada e resíduo de cerâmica vermelha em concretos de cimento Portland, no módulo de elasticidade dinâmico, na resistência à fadiga e na tenacidade à fratura. As adições contribuíram de maneira diferenciada para as propriedades analisadas, demonstrando não afetar negativamente o módulo de elasticidade dinâmico aos 28 dias. As adições tenderam a diminuir sensivelmente a resistência à tração na flexão.

As escórias de alto forno possuem propriedades hidráulicas; entretanto, tais reações são muito lentas, daí a necessidade dos ativadores e catalisadores para acelerá-las. Segundo Esper e Helene [6], os ativadores físicos atuam diretamente na temperatura e na finura das escórias. Já, os ativadores químicos (cal e sulfatos) favorecem a reatividade e participam da reação formando novos compostos. O hidróxido de sódio atua somente como um catalisador do processo.

No cimento Portland o sulfato de cálcio e a cal atuam como ativadores químicos [2]. O sulfato combina-se com o aluminato tricálcico $\left(\mathrm{C}_{3} \mathrm{~A}\right)$ do clínquer originando a etringita 
que se transformará em monosulfoaluminato cálcico. A cal liberada, $\mathrm{Ca}(\mathrm{OH})_{2}$ ou $\mathrm{CH}$, pela hidratação do $\mathrm{C}_{3} \mathrm{~S}$ e do $\mathrm{C}_{2} \mathrm{~S}$ constitui o principal ativador das escórias. $\mathrm{Na}$ seqüência $\mathrm{A}$, encontram-se listadas as reações de hidratação dos cimentos com escória:

$$
\begin{aligned}
& 2 \mathrm{C}_{3} \mathrm{~S}+6 \mathrm{H} \rightarrow \mathrm{C}_{3} \mathrm{~S} 23 \mathrm{H}+3 \mathrm{CH}, 100 \% \mathrm{C}_{3} \mathrm{~S} \rightarrow \\
& 49 \% \mathrm{CH}, 2 \mathrm{C}_{2} \mathrm{~S}+4 \mathrm{H} \rightarrow \mathrm{C}_{3} \mathrm{~S} 23 \mathrm{H}+\mathrm{CH}, \\
& 100 \% \mathrm{C}_{2} \mathrm{~S} \rightarrow 21 \% \mathrm{CH}, \mathrm{S} \rightarrow 21 \% \mathrm{CH}
\end{aligned}
$$

Quanto maior a quantidade de $\mathrm{C}_{3} \mathrm{~S}$, maior é o teor de $\mathrm{CH}$ liberado; essa característica é muito importante quando se utilizam cimentos com altos teores de escória. $\mathrm{O}$ composto químico denominado silicato de cálcio hidratado (C-S-H) sob a forma de gel constitui o principal produto de hidratação do cimento Portland com adição de escórias de alto forno, sendo responsável pela sua resistência mecânica. Encontra-se, ainda, como produto da hidratação o aluminato tetracálcico hidratado $\left(\mathrm{C}_{4} \mathrm{AH}_{13}\right), \mathrm{o} \mathrm{CH}$ e o monosulfoaluminato cálcico, que pode combinar-se com o $\mathrm{C}_{4} \mathrm{AH}_{13}$ formando soluções sólidas. Collins e Sanjayan [7] estudaram as propriedades de um concreto contendo escória ativada. Dois tipos de ativadores foram usados: o hidróxido de sódio em combinação com o carbonato de sódio e o silicato de sódio em combinação com a cal hidratada. Com um fator água/cimento de 0,5 a escória ativada com silicato de sódio apresentou uma perda mínima por abatimento acima de $2 \mathrm{~h}$. Já, a escória ativada com a solução líquida de silicato de sódio apresentou perda de trabalhabilidade inicial com perda de água por abatimento superior a $2 \mathrm{~h}$. $\mathrm{O}$ concreto dosado com escória ativada pela pasta de cal e silicato de sódio mostrou uma resistência à compressão similar ao do concreto de cimento Portland padrão na idade de 1 dia, apresentando uma resistência à compressão superior para idades mais avançadas. O concreto com escória ativada com carbonato de sódio e hidróxido de sódio teve um ganho moderado da resistência para idades de três dias. A retração por secagem dos concretos com ativadores de escória foi maior do que o concreto com cimento Portland padrão. Bakharev, Sanjanyan e Cheng [8] investigaram a ativação da escória australiana (AAS) pelos componentes à base de silicato de sódio, hidróxido de sódio, carbonato de sódio, fosfato de sódio e as combinações destes ativadores. $\mathrm{O}$ ativador mais eficaz foi o silicato de sódio líquido. Com base nesta investigação, concluiu-se pelo uso de uma solução do silicato de sódio com um baixo índice do Na para a formulação do concreto do AAS. Xinghua, Wenping, Chunxia et al. [9] estudaram o aumento da resistência do cimento Portland com adição de escória de alto forno e cinzas volantes "fly ash" com ativadores, tais como o sal do sódio, aluminato, gipsita calcinada e bauxita calcinada. Este cimento composto obteve um grande aumento de resistência. $\mathrm{O}$ sal de sódio aumentou a alcalinidade da solução e promoveu a despolimerização de escória de alto forno e do "fly ash". A bauxita calcinada se dissolveu e participou na hidratação. Os principais produtos de hidratação foram o CSH e os cristais de $\mathrm{CH}$ (portlandita), que embora em pouca quantidade, promoveram um aumento da resistência do cimento. $\mathrm{O} \mathrm{CH}$ reagiu com $\left(\mathrm{AlO}_{4}^{5-}\right)$ e $\left(\mathrm{SiO}_{4}^{4-}\right)$ despolimerizando a escória de alto forno e o "fly ash" para formar mais produtos e reforçar conseqüentemente a estrutura da pasta do cimento endurecido.

Argamassas industrializadas são produtos fabricados a partir de misturas homogêneas compostas por areias naturais ou artificiais, cal hidratada, cimento Portland e aditivos químicos. Elas são classificadas em argamassas tipo I, II, III e E [10]. A argamassa colante tipo I, é uma argamassa com menor teor de cimento e aditivos químicos, sendo indicada para aplicações de revestimentos cerâmicos em ambientes internos [11]. A do tipo II é utilizada para aplicações de revestimentos cerâmicos em ambientes internos e externos, possuindo características de adesividade que permitem absorver os esforços termo-higroscópicos e do vento, típicos de áreas externas. A argamassa tipo III serve para as aplicações de revestimentos cerâmicos em ambientes internos e externos, sendo composta por uma maior quantidade de cimento e aditivos químicos, proporcionando assim, uma aderência superior entre as interfaces em relação às argamassas tipo I e tipo II. A argamassa colante tipo E atende aos requisitos do tipo I, II ou III, com tempo em aberto estendido. Este último termo é subentendido como sendo o tempo máximo em que a argamassa conserva suas propriedades mínimas de aderência contadas após a abertura de um "pano" de argamassa fresca sobre um substrato de concreto. Antes da sua industrialização os revestimentos cerâmicos eram assentados com método convencional, utilizando uma mistura de areia e cimento ou, ainda, com adição da cal e eram feitas na própria obra. Neste caso, anterior ao assentamento, é necessário imergir as peças de revestimentos cerâmicos em um recipiente com água devido a sua falta de capacidade de reter em seu interior a quantidade de água necessária para uma boa hidratação do cimento. O método é considerado artesanal, complexo, de baixa produtividade e qualidade. Devido aos inúmeros desplacamentos de revestimentos cerâmicos de fachadas e pisos, muitas vezes causados pela mão de obra despreparada ou pela falta de controle na produção da argamassa feita em obra, surgiu no início da década de 70 a primeira argamassa colante do Brasil. Esta, veio acompanhada por um processo inovador que constituía no assentamento do revestimento cerâmico sem haver a necessidade de imergi-lo em água. Desde então, continuam os processos de pesquisa e desenvolvimento de novas tecnologias a fim de se ter uma argamassa específica para cada tipo de aplicação [11]. Dadas tais características técnicas favoráveis da incorporação da escória de alto forno ao cimento Portland, foi desenvolvida esta investigação no sentido de verificar, também, a sua viabilidade em argamassas colantes, tipo AC-I. Este produto tem um mercado nacional da ordem de 2 milhões de toneladas/ano, com perspectiva de crescimento de $10 \%$ para este ano. Outro apelo tecnológico do uso desta adição veio da possibilidade de redução do impacto ambiental e redução de energia consequentes das diminuições da exploração das jazidas de calcário e da emissão do $\mathrm{CO}_{2}$ na produção do clínquer [11]. 


\section{MATERIAIS E MÉTODOS}

Escória: três amostras de escória de alto forno foram provenientes do município de Cubatão, litoral do Estado de São Paulo, do município de Barcarena no Estado do Pará, e do estado de Minas Gerais. Estas se apresentavam em forma granulada e com um determinado teor de umidade e foram identificadas como $\mathrm{A}, \mathrm{B}$ e $\mathrm{C}$, porém, não na mesma ordem indicada por motivo de sigilo industrial. Foi necessário realizar a sua secagem em estufa a uma temperatura de $100^{\circ} \mathrm{C}$ até obter-se massa constante. Todas as amostras passaram por um processo de moagem em um moinho de bolas, 90 min velocidade de $750 \mathrm{rpm}$, a fim de se obter a finura aproximada à do cimento Portland. $O$ material de moagem foi composto por corpos moedores de aço com diâmetros compreendidos entre 20 e $77 \mathrm{~mm}$. Em seguida, as amostras foram submetidas ao teste de determinação da finura por intermédio do permeabilímetro de Blaine [10], que consiste em determinar o tempo que uma dada quantidade de ar leva para atravessar uma quantidade compacta de material, utilizando um aparelho de Blaine semi automático Tony Technik 6568.

Reatividade da escória de alto forno: para a realização do teste rápido, verificação e a classificação das reatividades das amostras de escória, por microscopia óptica, MO, foi utilizado um microscópio Olympus BX51, com luz refletida e transmitida com ocular de ampliação de 10 vezes e objetivas de ampliação de 10, 20, 40 e 100 vezes. O método consistiu na utilização de uma pequena fração de escória moída e peneirada com granulometria entre 53 e $63 \mu \mathrm{m}$, que foi pulverizada sobre uma lâmina com um líquido dispersante e recoberta com outra lâmina. A escória foi tratada com uma solução aquosa a $4 \%$ de sulfato de alumínio [12], marcandose o tempo do início da formação de cristais de gipsita a partir da reação do cálcio disponível nas escórias com o sulfato de alumínio, segundo a reação B:

$$
\mathrm{Ca}^{2+}+\mathrm{Al}_{2}\left(\mathrm{SO}_{4}\right)_{3 \mathrm{aq}} \rightarrow \mathrm{CaSO}_{4} \cdot 2 \mathrm{H}_{2} \mathrm{O} \text { (gipsita)+subprodutos }
$$

Com essa técnica foi possível classificar as escórias de acordo com a sua reatividade, em: alta reatividade - início da cristalização em tempo inferior a 3 min; média reatividade início da cristalização em intervalo de tempo de 3 a 5 min; e baixa reatividade - início da cristalização em tempo superior a 5 min.

Areia: foram utilizadas amostras de areia beneficiada e seca para a produção das argamassas industrializadas. Estas foram submetidas aos ensaios para a determinação do material fino que passa pela peneira $75 \mu \mathrm{m}$ por lavagem conforme a norma NBR NM 46 [10]. O teste para a obtenção do teor de impureza orgânica foi desenvolvido conforme a norma NBR NM 49 adaptada para a ASTM C-40, com teste colorímetro [10]. Nesse caso, uma amostra de areia foi misturada com uma solução de hidróxido de sódio a 3\%, ficando em seguida em repouso e protegida da luz para posteriormente ser comparada com um padrão de cores que determina em ppm a quantidade de material orgânico presente na areia. A determinação do módulo de finura consistiu no procedimento da soma das porcentagens acumuladas nas peneiras de série normal (76 a $0,15 \mathrm{~mm}$ ) segundo procedimentos indicados na norma NBR NM 248 [10].

Cimento Portland: foram utilizados dois tipos de cimento Portland; o CPII-F e o CPII-Z, comercializados no Brasil. Estes foram escolhidos pela sua abundância no mercado, representando quase $80 \%$ da produção nacional. O uso do cimento CPII-Z esteve fundamentado, também, nas suas características técnicas como de menor resistência inicial, menor calor de hidratação, maiores impermeabilidade, durabilidade e resistência aos meios agressivos, do que o CPII-F. As amostras de cimento foram caracterizadas pelas análises físicas e químicas, conforme as normas ABNT NBR 5752 e 5753 [10].

Cal: de acordo com a norma NBR 7175 [10], a cal hidratada pode ser classificada em três tipos: $\mathrm{CH}$ I, CH II e CH III, sendo que a cal CH III possui limites mais amplos para o anidrido carbônico $\left(\mathrm{CO}_{2}\right)$, para os óxidos totais na base não volátil e para os óxidos totais hidratados. Assim, uma cal mais "pura" quimicamente é a CH I, já que para ser definida desta maneira, seus resultados obedecem a limites acima dos exigidos para a CH III. O tipo CH II tem características químicas intermediárias aos outros dois.

Aditivo: foi utilizado como aditivo um éter de celulose (MHEC) metil hidróxi etil celulose de alta viscosidade, para atuar como retentor de água.

Composições: foram definidos nas composições os teores de cimento e de aditivo nas proporções intermediárias das utilizadas nas argamassas colantes do tipo AC-I, para utilizá-las como amostra padrão. Em seguida, foram fixadas as porcentagens de adição de escória à argamassa colante. Estas substituições foram realizadas em 6 teores diferentes (de 0 a 5), em cada qual acrescentando-se 5\%, em massa, de material onde 0 é a substituição mínima ( $0 \%$ de escória) e 5 a substituição total do cimento Portland. Como códigos, foram utilizados: o $\mathrm{Z}_{\mathrm{n}}$, quando a escória trabalhada foi a de baixa reatividade e o CPII-Z 32; o F , para a escória de baixa reatividade e o cimento CPII-F 32. Para as escórias de média e alta reatividade, foram utilizados os índices de 6 a 11, sendo os $Z_{6}, Z_{7}$ e $Z_{8}$ para os teores de $5 \%, 10 \%$ e $15 \%$ de escória de média reatividade, substituindo o CPII-Z 32; e os $Z_{9}, Z_{10}$ e $Z_{11}$, substituindo teores e cimento similares, mas com a escória de alta reatividade. Também, comparativamente, foram estudados 6 traços de mesma concentração química de materiais, mas, substituindo-se a escória de baixa reatividade com cal, sem cimento. Os códigos utilizados foram do $\mathrm{E}_{0}$ ao $\mathrm{E}_{5}$. Os traços foram misturados, aplicados e analisados de acordo com as normas NBR 14082, 14083 e 14084 [10]. Após esse processo as amostras foram misturadas nas proporções pré-definidas em um misturador tipo Y, por um período de 30 min para cada amostra. As amostras foram tratadas de acordo com as recomendações da norma NBR 14082 [10], até o momento do ensaio. Posteriormente, foram realizados os ensaios de viscosidade, determinação do tempo em aberto e determinação da resistência de aderência à tração conforme as normas NBR 14083 e 14084 [10]. 
Para a realização do ensaio de tração uniaxial direta sobre os traços de argamassas moldados utilizou-se um dinamômetro Proceq Dina Z6, a uma velocidade de carregamento de, aproximadamente, $250 \mathrm{~N} / \mathrm{s}$.

O ensaio para determinação do tempo em aberto consistiu na aplicação de uma argamassa colante industrializada, misturada de acordo com a norma NBR 14082 [10].

Para a determinação da resistência à tração da cura normal a argamassa permaneceu sob as condições descritas anteriormente por 28 dias, o que mudou foi, somente, o tempo para o carregamento inicial ( $5 \mathrm{~min}$ para todos os tipos de argamassa colante) e a absorção de água das peças cerâmicas utilizadas que possuíram uma menor faixa (3 a $5 \%$ ). No procedimento de cura normal foram reproduzidas as condições médias de temperatura e umidade a que uma argamassa colante está sujeita. Para a cura submersa o procedimento de ensaio foi igual ao da cura normal. Entretanto para este tipo de ensaio a placa de substrato padrão permaneceu 7 dias em condições controladas de laboratório e 21 dias submersa em um tanque de água com temperatura entre 21 e $25^{\circ} \mathrm{C}$. Neste caso, procurou-se reproduzir as condições de um revestimento cerâmico submetido a uma condição hídrica severa, tais como em cozinhas, banheiros e lavanderias.

Ensaios físicos e mecânicos [10]: os ensaios físicos e mecânicos para caracterização das amostras de cimento seguiram os procedimentos recomendados pelas respectivas normas técnicas. A determinação da massa específica foi realizada de acordo com a NM 23 [10]. A determinação da finura pelo método de Blaine foi realizado de acordo com a NM 76 [10]. Esse ensaio foi importante para se conhecer a velocidade de reação: quanto mais fino o cimento, maior a área total de superfície disponível para a hidratação e por conseqüência, maior a velocidade no aumento da resistência. Este aumento de velocidade da reação também deve ser conhecido e controlado, pois acarreta em grande aumento de temperatura e, conseqüentemente, no desprendimento de calor, o que pode causar fissuração na peça concretada. $\mathrm{O}$ ensaio de determinação da pasta de consistência normal foi realizado de acordo com a norma NM 43 [10]. A consistência da pasta é função da quantidade de água adicionada, da finura do material, da composição mineralógica, tipos e teores de adição, etc. $\mathrm{O}$ ensaio de determinação da expansibilidade foi realizado de acordo com a norma NBR 11582 [10], sendo desenvolvido para verificar a expansão consequente da hidratação do $\mathrm{CaO}$. O ensaio de determinação do tempo de pega foi realizado de acordo com a norma NM 65 [10]. A determinação do índice de finura por peneirador aerodinâmico foi realizado de acordo com a norma NBR 12826 [10]. A resistência à compressão axial foi executado de acordo com a norma NBR 72165 [10].

Identificação de fases e da composição química dos materiais trabalhados: a identificação das fases químicas dos materiais foi efetuada por difração de raios X (DRX). Esta técnica foi utilizada para caracterizar as espécies cristalinas formadas nas diferentes composições de argamassas testadas para a escória de baixa reatividade para os cimentos CPII-Z e CPII-F, na idade de 28 dias, e também, para a análise da cal. As análises foram realizadas em equipamento Philips X'Pert MPD. Os parâmetros empregados foram: velocidade de contagem de $20 \mathrm{~s}$ por passo em ângulos $2 \Theta$ entre $5^{\circ}$ e $70^{\circ}$ e com tempo de passo de $0,016 \%$. Como fonte de raios $\mathrm{X}$ foi utilizado o tubo cerâmico com anodo de cobre, com comprimento de onda $1,540598 \AA$, na potência máxima de $1600 \mathrm{~W}$.

A composição química das amostras foi identificada pela fluorescência de raios X (FRX), em equipamento Philips Magi'X-Pro PW2540. O material foi pulverizado e fundido em pastilha de bórax.

Microscopia eletrônica de varredura, MEV: foi utilizado um microscópio Philips XL 30, com microssonda analítica de raios X (EDS) EDAX. O preparo das amostras foi feito com o recobrimento superficial em carbono grafite na superfície de fratura. Foram analisados os traços de argamassa com escória de baixa reatividade e os cimentos do tipo CPII-Z e CPII-F, na idade de 28 dias.

Análise de metais e ensaio de lixiviação [10]: a análise de metais e de sua lixiviação foi realizada pelos métodos de determinação de elementos por chama, determinação de elementos por geração de hidretos e em forno de grafite. A determinação de fluoretos foi feita pela técnica de íons seletivos e o procedimento para a obtenção do extrato lixiviado foi realizado de acordo com a norma NBR 10005. A classificação das amostras de resíduos sólidos foi obtida de acordo com a norma NBR 10004.

Ensaio para a determinação da viscosidade: foi realizada em um viscosímetro Brookfield DV-II +. Para cada amostra foram feitas 200 leituras em $2 \mathrm{~s}$, utilizando o "Helipath spindle D", a uma velocidade de $6 \mathrm{rpm}$. Esse ensaio foi realizado para avaliar as características das adições no estado fresco, bem como compará-las com os padrões.

\section{RESULTADOS E DISCUSSÃO}

\section{Caracterização da escória}

Os resultados da caracterização das amostras de escória por FRX estão apresentados na Tabela I. Constatou-se que as três amostras de escória foram muito parecidas em termos de composição química, sendo as principais diferenças nos teores de óxido de ferro (mais alto) e óxido de magnésio (mais baixo) da escória A. Quanto aos outros óxidos metálicos sua investigação esteve centrada em possíveis contaminações ambientais, apesar de haver baixa concentração, tais como para os óxidos de cobalto, ítrio, bário e manganês. Também foram analisados os metais prata, cromo e arsênio, para avaliar seus desempenhos em termos de lixiviação, já que seus limites de detecção ambiental pela norma NBR 10004 [10] são verificados em ppm. Os resultados obtidos e reunidos na Tabela II indicaram que a concentração de metais lixiviados pela amostra de escória $\mathrm{C}$ esteve dentro dos limites especificados, não havendo, assim, a preocupação com a lixiviação de metais pesados para o meio ambiente [10]. Pela análise da reatividade das escórias concluiu-se que apesar das suas composições químicas terem sido similares, somente a escória $\mathrm{C}$ foi a menos reativa. As 
escórias B e A foram de média reatividade com um tempo de 4 min e 3,10 min, respectivamente. Altas reatividades podem influenciar na trabalhabilidade e aplicação em campo. Como exemplo do resultado analítico encontra-se mostrado na Fig. 1, os detalhes por MO da formação da gipsita, na amostra de escória C.

Tabela I - Caracterização química das escórias de alto forno por FRX, em percentual em massa.

[Table I-Chemical characterization of slags of high oven by $F R X$, in percentage in mass.]

\begin{tabular}{cccc}
\hline $\mathrm{Amostra}$ & Escória A & Escória B & Escória C \\
\hline $\mathrm{Na}_{2} \mathrm{O}(\%)$ & 0,15 & 0,16 & 0,15 \\
$\mathrm{MgO}(\%)$ & 1,25 & 5,00 & 4,79 \\
$\mathrm{Al}_{2} \mathrm{O}_{3}(\%)$ & 11,78 & 13,21 & 12,94 \\
$\mathrm{SiO}_{2}(\%)$ & 37,90 & 34,89 & 37,40, \\
$\mathrm{P}_{2} \mathrm{O}_{5}(\%)$ & 0,01 & 0,03 & 0,02 \\
$\mathrm{SO}_{3}(\%)$ & 2,47 & 1,94 & 1,92 \\
$\mathrm{~K}_{2} \mathrm{O}(\%)$ & 0,37 & 0,42 & 0,54 \\
$\mathrm{CaO}(\%)$ & 42,14 & 41,48 & 39,57 \\
$\mathrm{TiO}_{2}(\%)$ & 0,25 & 1,16 & 0,78 \\
$\mathrm{MnO}(\%)$ & 0,26 & 0,75 & 0,68 \\
$\mathrm{Fe}_{2} \mathrm{O}_{3}(\%)$ & 3,19 & 0,53 & 0,72 \\
$\mathrm{Co}_{3} \mathrm{O}_{4}(\%)$ & 0,00 & 0,05 & 0,00 \\
$\mathrm{SrO}_{(\%)}$ & 0,08 & 0,19 & 0,11 \\
$\mathrm{ZrO}(\%)$ & 0,04 & 0,04 & 0,04 \\
$\mathrm{Y}_{2} \mathrm{O}_{3}(\%)$ & 0,00 & 0,01 & 0,01 \\
$\mathrm{CL}(\%)$ & 0,00 & 0,00 & 0,08 \\
$\mathrm{BaO}(\%)$ & 0,11 & 0,15 & 0,16 \\
$\mathrm{Soma}$ & 100,00 & 100,00 & 100,00 \\
\hline & & &
\end{tabular}

Tabela II - Resultados do teor de metais lixiviados - escória C. [Table II - Results of the leached metal text - slag C.]

\begin{tabular}{ccccc}
\hline $\begin{array}{c}\text { Composição } \\
\text { Química }\end{array}$ & $\begin{array}{c}\text { Teor } \\
(\mathrm{mg} / \mathrm{L})\end{array}$ & $\begin{array}{c}\text { Limite } \\
\text { detecção } \\
\mathrm{mg} / \mathrm{L}\end{array}$ & $\begin{array}{c}\mathrm{NBR} 10004 \\
\mathrm{mg} / \mathrm{L}\end{array}$ \\
\hline Cádmio & $\mathrm{Cd}$ & N.D. & 0,00 & 0,5 \\
Mercúrio & $\mathrm{Hg}$ & N.D. & 0,0001 & 0,1 \\
Arsênio & $\mathrm{As}$ & 0,02 & 0,00 & 1 \\
Selênio & $\mathrm{Se}$ & 0,00 & 0,00 & 1 \\
Prata & $\mathrm{Ag}$ & 0,00 & 0,00 & 5 \\
Bário & $\mathrm{Ba}$ & 3,86 & 0,50 & 70 \\
Cromo & $\mathrm{Cr}$ & 0,06 & 0,001 & 5 \\
Chumbo & $\mathrm{Pb}$ & 0,00 & 0,00 & 1 \\
Fluoreto & $\mathrm{F}-$ & 3,52 & 0,02 & 150 \\
pH & - & 8,43 & - & - \\
\hline
\end{tabular}
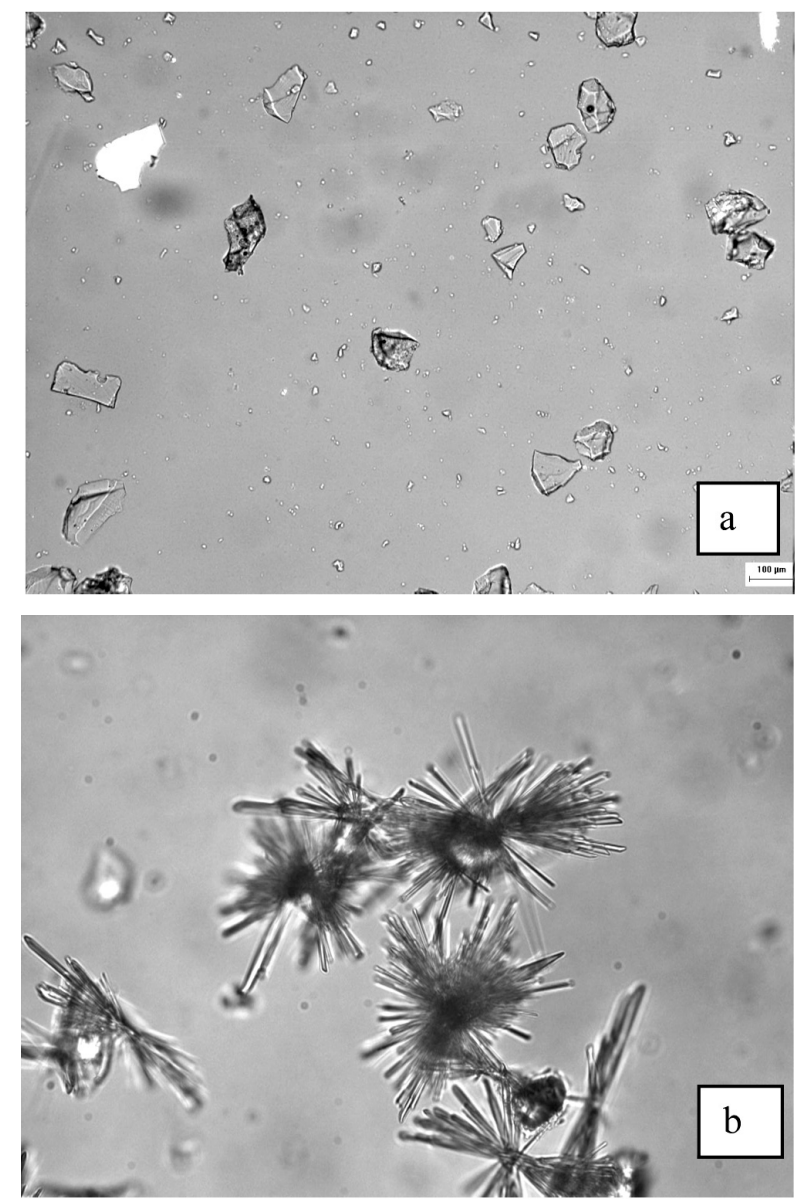

Figura 1: a) Aspectos da fração $100 \mu$ m da escória sob microscópio de luz transmitida; b) detalhes da cristalização da gipsita, amostra tratada com solução aquosa diluída de sulfato de alumínio, com aumento de 40 vezes.

[Figure 1: a) Aspects of fraction $100 \mu \mathrm{m}$ of the slag under microscope of transmitted light; $b$ ) details of the crystallization of crude gypsum, sample dealt with diluted watery solution of aluminum sulphate, with increase of 40 times.]

\section{Caracterização físico química dos insumos}

A areia analisada apresentou um baixo módulo de finura e a presença de impurezas abaixo do limite especificado em norma [8], sendo ideal para argamassas colantes industrializadas. Ambos os cimentos apresentaram resultados físicos e químicos dentro do especificado pelo fabricante e normas pertinentes [10]. Os resultados químicos indicaram que a cal CH II é de boa qualidade química, possuindo um percentual de óxidos totais na base de não voláteis $(\mathrm{CaO}+$ $\mathrm{MgO}$ ) de $94,31 \%$,sendo portanto,superior ao limite de $88 \%$ recomendado na norma NBR7175[10].

\section{Caracterização das amostras ou traços trabalhados}

\section{Viscosidade}

Na Fig. 2 encontram-se os dados de viscosidade dos traços de argamassas com incorporações de diferentes teores 
de adição de escória e cal. Foram verificadas, durante as suas aplicações, melhorias em termos de trabalhabilidade na medida em que se aumentou a proporção das adições de $5 \mathrm{a}$ $20 \%$. Isto se deveu, principalmente, pela característica vítrea dos grãos de escória de alto forno. As possíveis reações de hidratação e de formação dos géis $\mathrm{CSH}$ entre a cal $\mathrm{CH}$ III e os constituintes das escórias devem ter contribuído para a elevação da viscosidade da mistura, a partir do $\mathrm{E}_{1}$, inviabilizando seu uso em conseqüência da trabalhabilidade.

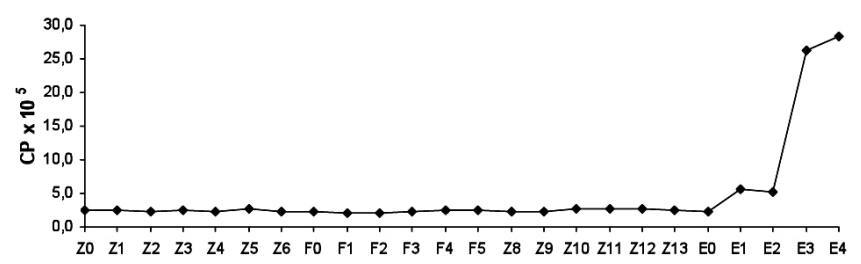

Figura 2: Gráfico representativo das viscosidades obtidas (centipoyse), variando-se as adições de escória.

[Figure 2: Representative graph of evaluated viscosities (centipoyse), varying the slag additions.]

\section{Resultados de resistência de aderência à tração e tempo em aberto}

A resistência de aderência das argamassas foi independente da reatividade das escórias. Foram obtidos resultados acima dos valores de norma com adições de até $15 \%$ para todos os tipos trabalhados, (baixa, média e de alta reatividade). Como mostrado na Fig. 3 para a argamassa com escória C, o cimento Portland CP II-F apresentou um desempenho superior (entre 0,1 e $0,5 \mathrm{MPa}$ ) ao $\mathrm{CP}$ II-Z em termos de resistência de aderência à tração. Este comportamento é conseqüente da sua maior área específica e pela sua maior quantidade de clinquer (entre 90 e 94\%). As substituições $F_{1}$ à $F_{3}$ apresentaram resultados de aderência, semelhantes à amostra padrão, com pequena tendência de diminuição de desempenho pelo aumento da adição. $\mathrm{O}$ teor ótimo de adição para os cimentos CP II - F e de CP II - Z foi de $5 \%$ apresentado nos traços $\mathrm{F}_{1}$ e $\mathrm{Z}_{1}$, respectivamente. As amostras com até $20 \%$ de substituição de cimento por escória atenderam aos valores de resistência de aderência à tração e tempo em aberto, estabelecidos pela norma NBR 14081 [10]. A amostra $Z_{5}$ apresentou o pior desempenho, podendo ser descartada do conjunto. Todos os traços feitos somente com escória e cal apresentaram resultados de resistência de aderência à tração e ou tempo em aberto inferiores a $0,5 \mathrm{MPa}$, portanto abaixo dos valores estabelecidos pela norma NBR 14081 [10], indicando assim, a inviabilidade da produção de argamassas colantes sem adição de cimento Portland. Uma vez avaliada a influência do tipo de cimento na resistência de aderência à tração e do tempo em aberto das argamassas colantes, avaliou-se também a influência da reatividade das escórias. Foram escolhidos os 3 traços que tiveram os melhores resultados com a escória de baixa reatividade $(5,10$ e $15 \%)$. Optou-se por fixar o cimento
CP II-Z como padrão. Os resultados foram similares e, em média, foram de $(1,0 \pm 0,1) \mathrm{MPa}$, independentemente do tipo e teor de escória trabalhados. Os valores encontram-se dentro do recomendado em norma [10].
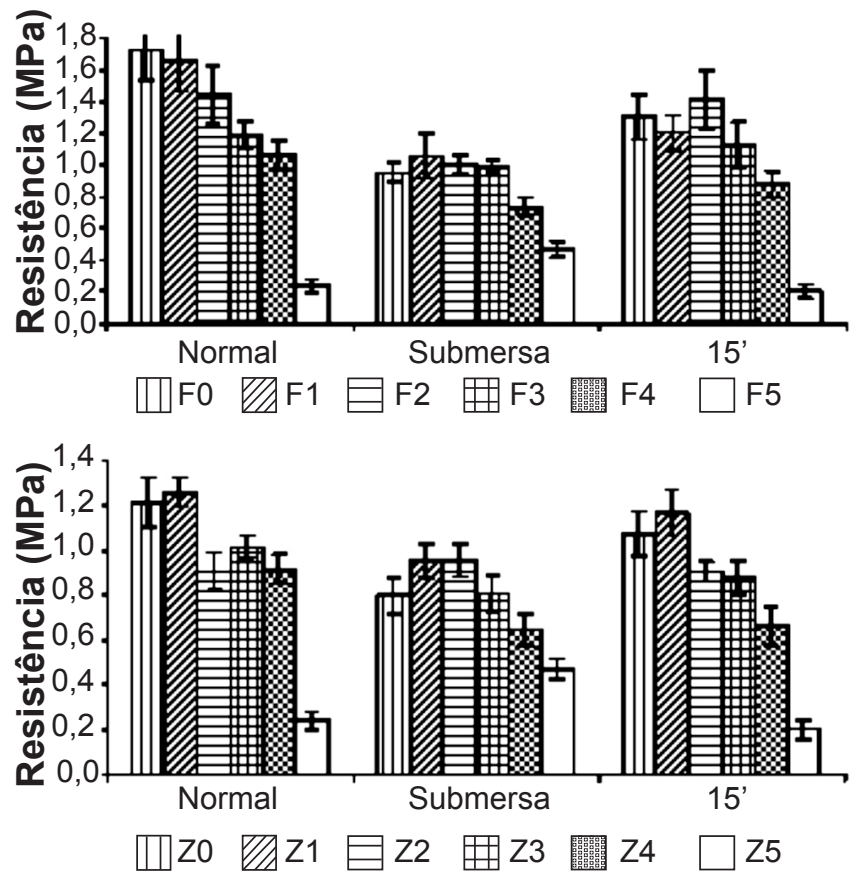

Figura 3: Resistência de aderência à tração e tempo em aberto dos traços com CPII-Z, CPII-F com a escória C.

[Figure 3: Resistance of tack to the traction and opened time in of the traces with CPII-Z, CPII-F with slag C.]

Para comprovar a importância da cal como ativador das escórias foi desenvolvida mais uma série de amostras, iniciando-se pela amostra padrão composto pela escória $\mathrm{C}$ e areia de quartzo e as demais adições de cal CH III. A adição de 5\% de cal à argamassa ocasionou um aumento da sua consistência, duplicando a sua viscosidade em relação à amostra padrão para aproximadamente 5,6x105 cP. Procurou-se, então, aumentar o teor de água nas misturas e, mesmo assim, foram obtidos valores de consistência 12 vezes maior em relação ao padrão, o que prejudicou o tempo em aberto e a trabalhabilidade da argamassa. Nenhum dos resultados obtidos foi satisfatório quando confrontado com os valores de norma [10].

\section{$D R X, M E V$ e EDS}

$\mathrm{Na}$ argamassa endurecida foram identificadas, principalmente, as fases químicas quartzo $\left(\mathrm{SiO}_{2}\right)$, calcita $\left(\mathrm{CaCO}_{3}-\mathrm{CC}\right)$, larnita $\left(\mathrm{Ca}_{2} \mathrm{SiO}_{4}-\mathrm{C}_{2} \mathrm{~S}\right)$ e brownmilerita (4CaO $\left.\cdot \mathrm{Al}_{2} \mathrm{O}_{3} \cdot \mathrm{Fe}_{2} \mathrm{O}_{3}-\mathrm{C}_{4} \mathrm{AF}\right)$, típicas de composições à base de cimento Portland. As investigações por MEV revelaram micrografias com quantidade e tamanho regulares de poros, preenchidos, em sua maioria, por uma composição química elementar (\% atômica) determinada por análise 
semiquantitativa por EDS, por O $(52,4 \%), \mathrm{Mg}(1,2 \%)$, $\mathrm{Al}(1,5 \%), \mathrm{Si}(3,9 \%)$ e Ca $(41,0 \%)$. Na Fig. 4 é ilustrada uma das superfícies identificadas e, em destaque, o interior de um dos poros da região. Este tipo de textura facilita o trabalho de aplicação pela maior superfície de contato aos substratos.

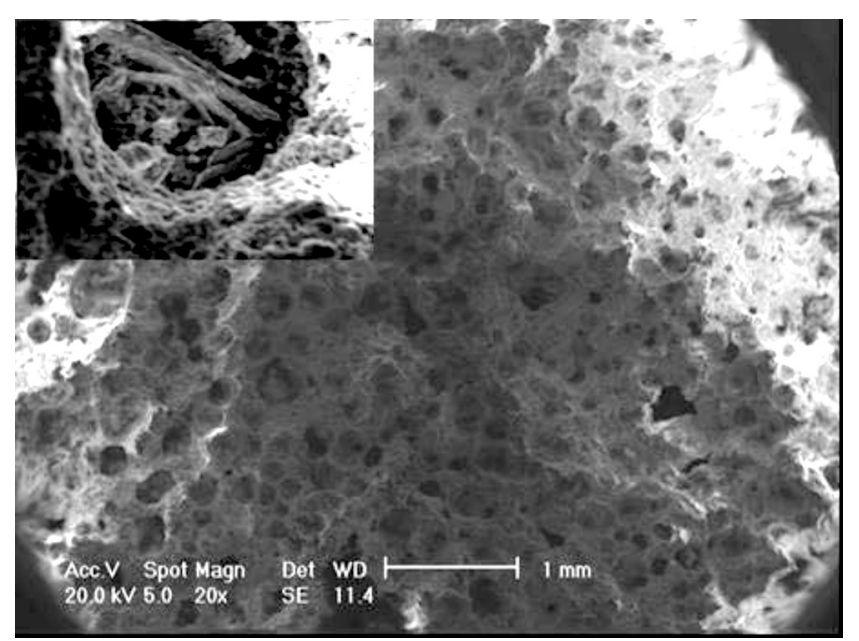

Figura 4: Micrografia, por MEV, da superfície de fratura de uma das amostras de argamassa endurecida, com aumento de 20 vezes. Em destaque, um dos poros ampliados $(500 \mathrm{x})$.

[Figure 4: SEM micrograph of the surface of breaking of one of the hardened mortar samples, with 20x magnitude. In detail, one of the extended pores $(500 x)$.]

\section{CONCLUSÕES}

A adição de escória de alto forno em substituição ao cimento Portland em argamassas colantes do tipo AC I não alterou as características ideais em termos de viscosidade. Foram verificadas, durante as suas aplicações, melhorias em termos de trabalhabilidade pelo aumento da proporção das adições de 5 a $20 \%$. O teor ótimo de adição para os cimentos CP II - F, e CP II - Z foi $5 \%$. No entanto as amostras com até $20 \%$ de substituição de cimento por escória atenderam aos valores de resistência de aderência à tração e tempo em aberto, estabelecidos em norma. É possível produzir uma argamassa colante industrializada de maneira sustentável, com redução de poluentes ambientais pela diminuição do teor de cimento nos traços com adições e, também, pelo uso de resíduos da área metalúrgica.

\section{REFERÊNCIAS}

[1] http://www.ibs.org.br , acessado em 22/09/2008.

[2] A. M. Neville, Propriedades do Concreto. $2^{\mathrm{a}}$ Ed., Editora Pini, S. Paulo, SP (1997).

[3] R. Sersale, Characterization and potential uses of steel slag. Silicates Industriels 51 (1986)163-170.

[4] J. S. Reschke, Escória Granulada de Fundição Utilizada como Substituição ao Cimento em Concretos: avaliação de propriedades relacionadas com a durabilidade, Diss. Mestrado, UFRGS (2003).

[5] J. Chamon, Estudo da Influência de Adições no Módulo de Elasticidade Dinâmico, na Resistência à Fadiga e na Tenacidade à Fratura para Concretos Convencionais, Diss. Mestrado, UFMG (2006).

[6] M. W. Esper, P. Helene, Características do Cimento Portland de Alto-Forno, Bol. Técnico da EPUSP, Dep. Eng. Constr. Civil, S. Paulo, SP (1993).

[7] F. G. Collins, J. G. Sanjanyan, Workability and mechanical properties of alkali activated slag concrete, Cement Concrete Res. 29 (1999) 455-458.

[8] T. Bakharev, J. Sanjanyan, Yi-Bing Cheng, Alkali activation of Australian slag cements, Cement Concrete Res. 29 (1999) 113-120.

[9] Fu Xinghua, Hou Wenping, Yang Chunxia, Li Dongxue, $\mathrm{Wu}$ Xuequan, Studies on high-strength slag and fly ash compound cement, Cement Concrete Res. 30 (2000) 12391243.

[10] Assoc. Bras. Normas Técnicas: ABNT NBR NM 23, Rio de Janeiro (2001); ABNT NBR NM 43, Rio de Janeiro (2003); ABNT NBR NM 46, Rio de Janeiro (2003); ABNT NBR NM 49, ABNT NBR NM 65, Rio de Janeiro (2003); ABNT NBR NM 76, Rio de Janeiro (1998); Rio de Janeiro (2001); ABNT NBR NM 248, Rio de Janeiro (2003); ABNT NBR 7175, Rio de Janeiro (2003); ABNT NBR 5752, Rio de Janeiro (1992); ABNT NBR 5753, Rio de Janeiro (1992); ABNT NBR 10004, Rio de Janeiro (2001); ABNT NBR 10005, Rio de Janeiro (2001); ABNT NBR 11852, Rio de Janeiro (1991); ABNT NBR 12826, Rio de Janeiro (1993); ABNT NBR 14081, Rio de Janeiro (2004); ABNT NBR 14083, Rio de Janeiro (2004); ABNT NBR 14084, Rio de Janeiro (2004); ABNT NBR 72165, Rio de Janeiro (1996); [11] J. Rossa Jr., Adição de escória de alto forno em argamassa colante ACI, Diss. Mestrado, UFPR (2009).

[12] A. F. Battagin, Método microscópico rápido para verificação da reatividade de escórias de alto forno, Bol. Inf. Microscopia 3, S. Paulo, SP (1984).

(Rec. 19/04/2011, Ac. 03/09/2011) 